\title{
ESTADO DE EXCEÇÃO - ESTUDO DE CASO
}

\section{Cláudia Honório*}

\begin{abstract}
RESUMO
Duas recentes decisões proferidas pelo Supremo Tribunal Federal destacaram-se por referenciar, na fundamentação, a teoria do estado de exceção, estudada por Giorgio Agamben. Para verificar a adequação dos argumentos trazidos pelos julgados com a teoria evocada, cabe compreender a figura do estado de exceção, esta zona de indeterminação entre o direito e a vida, a norma e a anomia. Expondo aspectos da doutrina da Agamben, cabe questionar se as decisões da Corte correspondem com fidelidade ao intento da pesquisa desenvolvida nos livros "Homo Sacer - Poder soberano e vida nua" e "Estado de exceção". Verifica-se a aplicabilidade da noção de estado de exceção a casos considerados pelo tribunal como exceções à regra. Aventase, ao final, que o tribunal poderia obter as mesmas decisões mediante argumentação mais coerente.
\end{abstract}

Palavras-chave: soberania; exceção; estado de exceção.

SuMÁRIO: 1 CONSIDERAÇÕES INICIAIS; 2 AS DECISÕES EXCEPCIONAIS PROFERIDAS PELO SUPREMO TRIBUNAL FEDERAL; 3 ALGUNS ASPECTOS DA TEORIA DO ESTADO DE EXCEÇÃO; 4 PARALELO CONCLUSIVO ENTRE TEORIA E PRÁTICA: UM ABISMO? 5 REFERÊNCIAS.

\footnotetext{
* Bacharel em Direito pela UFPR. Especialista em Direito Constitucional pela UniBrasil.
} 


\section{CONSIDERAÇÕES INICIAIS}

O objetivo do presente artigo é analisar dois julgados recentes proferidos pelo Supremo Tribunal Federal fundamentados na teoria do estado de exceção. O enfoque interessa por tratar de tema atual, relevante e ao mesmo tempo preocupante - a constatação, pelo STF, de que se vive em um estado de exceção.

Giorgio Agamben, filósofo italiano, propõe-se estudar o estado de exceção, uma figura que está entre o jurídico e o político, o direito e a vida. $\mathrm{O}$ autor realiza uma série de escritos sobre situações-limite, focalizando a relação entre direito e anomia. É sobre aspectos dos dois primeiros escritos dessa série - "Homo sacer - poder soberano e vida nua" e "Estado de exceção" - que versará a presente análise, pois os temas ali postos foram expostos nas decisões a serem referidas.

Serão apresentados os julgados e suas referências às situações de exceção. Então, pretende-se expor (atendendo à limitação do número de páginas), alguns aspectos do estudo realizado por Agamben, no que dizem respeito aos acórdãos citados. Ao final, intenta-se verificar a adequação e a coerência dos julgados, contrapondo os argumentos evocados e as considerações doutrinárias desenvolvidas.

\section{AS DECISÕES EXCEPCIONAIS PROFERIDAS PELO SUPREMO TRIBUNAL FEDERAL}

O primeiro caso a ser analisado iniciou-se com o ajuizamento de ação de cobrança contra o Estado da Paraíba, por portadora de uma doença grave e incurável. A autora requereu a quitação de seu precatório por estar em condições críticas de saúde, necessitando de recursos financeiros para custear tratamento. O Tribunal de Justiça determinou o seqüestro de verbas para quitar o precatório.

Mestranda em Direito do Estado na UFPR. Bolsista da CAPES. E-mail: adv_claudiah@yahoo.com.br 
O governo estadual ajuizou Reclamação perante o Supremo Tribunal Federal, alegando que o Presidente do Tribunal de Justiça, ao determinar o seqüestro do valor de $\mathrm{R}$ \$ 356.940,13 para o pagamento do precatório, desrespeitou a decisão da Corte no julgamento da Ação Direta de Inconstitucionalidade $n^{0}$ 1.662. Na referida ADIn, decidiu-se que, diante de precatório de natureza alimentar, a única modalidade de seqüestro constitucionalmente admitida é a de preterimento do direito de preferência do credor, e tal preterimento não ocorreu no caso em apreço para justificar o seqüestro. O seqüestro foi deferido em razão da doença grave e incurável da credora, e não de quebra da ordem cronológica de pagamentos.

O Ministro Sepúlveda Pertence negou seguimento ao pedido, considerando que o ato reclamado, apesar da proximidade da matéria - seqüestro de valores de precatório -, não guarda identidade com o ato normativo impugnado na ADIn $\mathrm{n}^{\mathrm{o}}$ 1.662, o que impede o conhecimento do caso pela via da Reclamação. Em face dessa decisão, foi ajuizado Agravo Regimental, em que o Estado da Paraíba alega ser suficiente a proximidade da matéria entre o caso examinado e o paradigma apontado para justificar a Reclamação. Do julgamento do Agravo, interessa especificamente o voto proferido pelo Ministro Eros Grau, do qual se destacam os aspectos seguintes.

O Supremo Tribunal Federal, por seus julgados anteriores, firmou entendimento de caber o seqüestro de verbas públicas apenas na ocorrência de preterição ao direito de preferência. No caso em exame, o seqüestro não foi ordenado por esse motivo. Então, o Ministro Eros Grau alude que seria coerente votar pelo provimento ao Agravo, atribuindo razão ao Estado da Paraíba.

No entanto, afirma o Ministro que a situação de fato trazida nos autos tratase de uma exceção, e bem se sabe que as normas só valem para situações normais. Citando Agamben, explica que "O estado de exceção é uma zona de indiferença entre o caos e o estado da normalidade, uma zona de indiferença capturada pela norma. De sorte que não é a exceção que se subtrai à norma, mas ela que, suspendendo-se, dá lugar à exceção - apenas desse modo ela se constitui como 
regra, mantendo-se em relação com a exceção"1 (grifo nosso). Continuando, anuncia que ao Supremo Tribunal Federal, "sempre que necessário, incumbe decidir regulando também essas situações de exceção. Ao fazê-lo, não se afasta do ordenamento, eis que aplica a norma à exceção desaplicando-a, isto é, retirando-a da exceção",2 (grifo nosso).

Em face do quadro de exceção considerado, o Ministro negou provimento ao Agravo Regimental e julgou improcedente a Reclamação. Os Ministros do Supremo Tribunal Federal negaram, por unanimidade, o Agravo Regimental, mantendo o entendimento do Tribunal de Justiça da Paraíba, pelo seqüestro. A decisão, proferida em 21 de setembro de 2006, recebeu a seguinte ementa:

Reclamação: seqüestro de valores do Estado da Paraíba: alegação de desrespeito do julgado do Supremo Tribunal na ADIn 1.662 (Pleno, Maurício Corrêa, DJ 19.9.03): improcedência. Os fundamentos do ato reclamado, que determinou o seqüestro de valores para pagamento de precatório oriundo de ação de cobrança ajuizada perante a Justiça comum estadual, não guardam identidade com o ato normativo invalidado pelo acórdão da ADIn 1.662 (Instrução Normativa 11/97, aprovada pela Resolução 67/97, do Tribunal Superior do Trabalho), o que inviabiliza o exame da matéria na via estreita da reclamação.

(Agravo Regimental na Reclamação no 3034/PB, julgado pelo Tribunal Pleno do Supremo Tribunal Federal em 21/09/06, relator Ministro Sepúlveda Pertence. DJ 27/10/06, p. 31)

O segundo caso a ser considerado, mais recente, consiste na Ação Direta de Inconstitucionalidade $\mathrm{n}^{\mathbf{0}}$ 3.689, ajuizada pelo Partido do Movimento Democrático Brasileiro - PMDB, tendo por objeto a declaração de inconstitucionalidade da Lei $n^{\circ}$ 6.066, de 14 de agosto de 1997, do Estado do Pará. A lei impugnada altera divisas municipais, estabelecendo o desmembramento de faixa de terra do Município de Água Azul do Norte e a respectiva integração ao Município de Ourilândia do Norte.

A inconstitucionalidade é sustentada em face de suposta ofensa ao $\S 4^{\circ}$ do artigo 18 da Constituição Federal $^{3}$, que se refere a lei complementar federal para

${ }^{1}$ AGAMBEN, Giorgio. Homo Sacer - O poder soberano e a vida nua. Trad. Henrique Burgo. Belo Horizonte: UFMG, 2004, p. 26-27.

${ }^{2}$ Ibidem, p. 25.

${ }^{3}$ Constituição Federal de 1988: “Art. 18 - A organização político-administrativa da 
disciplina do período no qual Municípios podem ser criados, incorporados e desmembrados. Contudo, tal lei complementar ainda não existe, o que vedaria a disciplina da matéria por lei estadual. Ainda, a afronta à Constituição adviria da constatação de que somente a população residente na faixa de terra desmembrada do Município de Água Azul do Norte manifestou-se em plebiscito.

Do julgamento, realizado em 10 de maio de 2007, destaca-se o voto do Ministro Eros Grau, que novamente suscitou a teoria do estado de exceção. De seu posicionamento extraem-se as considerações seguintes.

A Lei estadual $n^{\circ} 6.066 / 97$ realizou a integração formal de fração do Município de Água Azul do Norte ao Município de Ourilândia do Norte. Todavia, lembra o Ministro, antes da disposição normativa já havia tal integração no mundo dos fatos, há mais de nove anos, pois era ao Município de Ourilândia do Norte que os que viviam na faixa de terra integrada recorriam para prover suas necessidades essenciais. Dessa forma, o Ministro Eros Grau assinalou que a Corte não poderia apenas realizar um exercício de subsunção, caminhando contra situação já consolidada no mundo dos fatos. Assim, entendeu estar diante de uma situação de exceção, em que conseqüências gravosas adviriam de eventual declaração de inconstitucionalidade da lei estadual.

O Ministro ressaltou que o direito positivo brasileiro acolhe algumas situações de exceção, como o casamento putativo e as sociedades de fato ou irregulares; apesar de serem atos contrários ao direito, deles advêm efeitos jurídicos, excepcionalmente. No caso do território incorporado ao Município de Ourilândia do Norte, está-se "diante de uma situação excepcional não prevista pelo direito positivo, porém instalada pela força normativa dos fatos" (grifo nosso).

O Município de Ourilândia do Norte administra a mencionada porção de terra

República Federativa do Brasil compreende a União, os Estados, o Distrito Federal e os Municípios, todos autônomos, nos termos desta Constituição. (...) $\S 4^{\circ}$ A criação, a incorporação, a fusão e o desmembramento de Municípios, far-se-ão por lei estadual, dentro do período determinado por Lei Complementar Federal, e dependerão de consulta prévia, mediante plebiscito, às populações dos Municípios envolvidos, após divulgação dos Estudos de Viabilidade Municipal, apresentados e publicados na forma da lei (Redação dada pela Emenda Constitucional nº 15, de 1996)." (grifo nosso) 
desde 1997. Não se poderia, agora, anular integração já ocorrida. A agregação violou a regra constitucional, é verdade, mas produz efeitos. Assim, essa realidade não está fora, mas dentro do ordenamento jurídico. Então, explica Eros Grau, citando Giorgio Agamben: "É que o estado de exceção é uma zona de indiferença entre o caos e o estado da normalidade, zona de indiferença capturada pela norma. De sorte que não é a exceção que se subtrai à norma, mas ela que, suspendendo-se, dá lugar à exceção - apenas desse modo ela se constitui como regra, mantendo-se em relação com a exceção"4 (grifo nosso).

Em comentário relevante, afirma o Ministro que "A esta Corte, sempre que necessário, incumbe decidir regulando também essas situações de exceção. Mas esta Corte, ao fazê-lo, não se afasta do ordenamento, eis que aplica a norma à exceção desaplicando-a, isto é, retirando-a da exceção" (grifo nosso). Ao concretizar a Constituição, "a Corte aplica-se a prover a sua força normativa e sua função estabilizadora, reportando-se à integridade da ordem concreta da qual ela é a representação mais elevada no plano do direito posto. A sua mais prudente aplicação, nas situações de exceção, pode corresponder exatamente à desaplicação de suas normas a essas situações" (grifo nosso).

A situação em exame é considerada excepcional pelo Ministro também pelo fato de que, em razão da omissão do Poder Legislativo em editar a lei complementar aludida na Constituição Federal, não se pode criar, incorporar, fundir ou desmembrar Municípios. E sendo a República Federativa do Brasil composta pela união indissolúvel dos Estados, Municípios e Distrito Federal, a omissão legislativa, ao impedir a formação de Municípios, acaba por violar a própria ordem constitucional.

No caso, não sendo possível anular a decisão política sem agredir o princípio federativo, torna-se sem sentido declarar a inconstitucionalidade da norma. Comprometeria mais a força normativa da Constituição a violação ao princípio federativo do que a agressão à regra do $\S 4^{\circ}$ do artigo 18. Assim, concluiu o Ministro pela improcedência da Ação Direta de Inconstitucionalidade.

\footnotetext{
${ }^{4}$ AGAMBEN, op. cit., p. 26-27.
} 
Após, votou o Ministro Gilmar Ferreira Mendes, no sentido de declarar a inconstitucionalidade da norma sem pronúncia de nulidade, mantendo a vigência do dispositivo legal pelo prazo de vinte e quatro meses, para que o legislador estadual reaprecie o tema, tendo como base os parâmetros que deverão ser fixados em lei complementar federal. Tal decisão derivou da possibilidade de modulação dos efeitos da declaração de inconstitucionalidade, compatibilizando proporcionalmente os princípios da nulidade da lei inconstitucional e da segurança jurídica. Diante desse pronunciamento, o Ministro Eros Grau alterou seu entendimento, concluindo também pela declaração de inconstitucionalidade sem pronúncia de nulidade. A decisão atribuída ao caso, por unanimidade de votos, recebeu a seguinte ementa:

AÇÃO DIRETA DE INCONSTITUCIONALIDADE. LEI N. 6.066, DO ESTADO DO PARÁ, QUE ALTERANDO DIVISAS, DESMEMBROU FAIXA DE TERRA DO MUNICÍPIO DE ÁGUA AZUL DO NORTE E INTEGROU-A AO MUNICÍPIO DE OURILÂNDIA DO NORTE. INCONSTITUCIONALIDADE DE LEI ESTADUAL POSTERIOR À EC 15/96. AUSÊNCIA DE LEI COMPLEMENTAR FEDERAL PREVISTA NO TEXTO CONSTITUCIONAL. AFRONTA AO DISPOSTO NO ARTIGO $18, \S 4^{\circ}$, DA CONSTITUIÇÃO DO BRASIL. OMISSÃO DO PODER LEGISLATIVO. EXISTÊNCIA DE FATO. SITUAÇÃO CONSOLIDADA. PRINCÍPIO DA SEGURANÇA DA JURÍDICA. SITUAÇÃO DE EXCEÇÃO, ESTADO DE EXCEÇÃO. A EXCEÇÃ̃O NÃO SE SUBTRAI À NORMA, MAS ESTA, SUSPENDENDO-SE, DÁ LUGAR À EXCEÇÃO --- APENAS ASSIM ELA SE CONSTITUI COMO REGRA, MANTENDO-SE EM RELAÇÃO COM A EXCEÇÃO.

1. A fração do Município de Água Azul do Norte foi integrada ao Município de Ourilândia do Norte apenas formalmente pela Lei estadual n. 6.066, vez que materialmente já era esse o município ao qual provia as necessidades essenciais da população residente na gleba desmembrada. Essa fração territorial fora já efetivamente agregada, assumindo existência de fato como parte do ente federativo --- Município de Ourilândia do Norte. Há mais de nove anos.

2. Existência de fato da agregação da faixa de terra ao Município de Ourilândia do Norte, decorrente da decisão política que importou na sua instalação como ente federativo dotado de autonomia. Situação excepcional consolidada, de caráter institucional, político. Hipótese que consubstancia reconhecimento e acolhimento da força normativa dos fatos.

3. Esta Corte não pode limitar-se à prática de mero exercício de subsunção. A situação de exceção, situação consolidada --- embora ainda não jurídica --- não pode ser desconsiderada.

4. A exceção resulta de omissão do Poder Legislativo, visto que o impedimento de criação, incorporação, fusão e desmembramento de Municípios, desde a promulgação da Emenda Constitucional n. 15, em 12 de setembro de 1996, deve-se à ausência de lei complementar federal.

5. Omissão do Congresso Nacional que inviabiliza o que a Constituição autoriza: o 
desmembramento de parte de Município e sua conseqüente adição a outro. A não edição da lei complementar dentro de um prazo razoável consubstancia autêntica violação da ordem constitucional.

6. A integração da gleba objeto da lei importa, tal como se deu, uma situação excepcional não prevista pelo direito positivo.

7. O estado de exceção é uma zona de indiferença entre o caos e o estado da normalidade. Não é a exceção que se subtrai à norma, mas a norma que, suspendendose, dá lugar à exceção --- apenas desse modo ela se constitui como regra, mantendo-se em relação com a exceção.

8. Ao Supremo Tribunal Federal incumbe decidir regulando também essas situações de exceção. Não se afasta do ordenamento, ao fazê-lo, eis que aplica a norma à exceção desaplicando-a, isto é, retirando-a da exceção.

9. Cumpre verificar o que menos compromete a força normativa futura da Constituição e sua função de estabilização. No aparente conflito de inconstitucionalidades impor-se-ia o reconhecimento do desmembramento de gleba de um Município e sua integração a outro, a fim de que se afaste a agressão à federação.

10. O princípio da segurança jurídica prospera em benefício da preservação do Município.

11. Princípio da continuidade do Estado.

12. Julgamento no qual foi considerada a decisão desta Corte no MI n. 725 , quando determinado que o Congresso Nacional, no prazo de dezoito meses, ao editar a lei complementar federal referida no $\S 4^{\circ}$ do artigo 18 da Constituição do Brasil, considere, reconhecendo-a, a existência consolidada do Município de Luís Eduardo Magalhães. Declaração de inconstitucionalidade da lei estadual sem pronúncia de sua nulidade.

13. Ação direta julgada procedente para declarar a inconstitucionalidade, mas não pronunciar a nulidade pelo prazo de 24 meses, da Lei n. 6.066, de 14 de agosto de 1997, do Estado do Pará.

(Ação Direta de Inconstitucionalidade ${ }^{\circ}$ 3.689/PA, julgada pelo Tribunal Pleno do Supremo Tribunal Federal em 10/05/07, relator Min. Eros Grau. DJ 29/06/07, p. 22 - grifo nosso)

Constata-se que duas situações fáticas completamente distintas - seqüestro de verbas públicas para pagamento de precatório e alteração na demarcação de Municípios - foram julgadas com base em idêntico fundamento suscitado pelo Ministro Eros Grau: a teoria do estado de exceção. Os casos foram considerados excepcionais à incidência das normas jurídicas e, assim, afastaram-se as regras.

Cabe expor, sucintamente, aspectos da teoria do estado de exceção, na esteira da formulação de Giorgio Agamben, para, então, traçar um paralelo entre esse discurso e aqueles proferidos pelo Supremo Tribunal Federal, a fim de se concluir pela (in)coerência dos argumentos expostos nos julgados. 


\section{ALGUNS ASPECTOS DA TEORIA DO ESTADO DE EXCEÇÃO}

O primeiro capítulo de "Homo Sacer - poder soberano e vida nua" trata da lógica da soberania. Agamben parte do enunciado de Carl Schmitt: soberano é aquele que decide sobre o estado de exceção. Schmitt enuncia a noção de soberania a partir da exceção, pois a soberania reside no fato de o Estado ter o monopólio da decisão extrema. A autoridade do Estado não precisa do direito para criar o direito, trata-se de uma decisão política. $O$ ato do soberano - a exceção soberana - é uma decisão que afirma sua autoridade e que não pertence ao direito.

Constata-se, então, a problemática de o soberano estar, ao mesmo tempo, dentro e fora do ordenamento jurídico: "Se o soberano é, de fato, aquele no qual o ordenamento jurídico reconhece o poder de proclamar o estado de exceção e de suspender, deste modo, a validade do ordenamento, então 'ele permanece fora do

ordenamento jurídico e, todavia, pertence a este, porque cabe a ele decidir se a constituição in toto possa ser suspensa." Está fora porque pode suspender a validade do ordenamento, e está dentro porque é o ordenamento jurídico que reconhece o poder de proclamar o estado de exceção e de suspender o direito.

A estrutura da soberania é a exceção, que marca uma zona de indeterminação entre direito e vida, ordem e caos, interior e exterior, inclusão e exclusão. O estado de exceção é o lugar no qual essa ambigüidade se mostra, tornando indistintos estado de natureza e estado de direito. Estabelece o nexo entre violência e direito e, ao mesmo tempo, rompe esse nexo, porque fica num limiar.

Diante dessas questões, Agamben constata que a exceção que define a estrutura da soberania é complexa. A relação da exceção com a regra é de uma exclusão inclusiva, pois o que é excluído do estado de direito, do direito vigente, não deixa de se relacionar com o direito, pois o suspende. Nessa situação, a regra aplica-se justamente pela sua desaplicação: 
Aquilo que está fora vem aqui incluído não simplesmente através de uma interdição ou de um internamento, mas suspendendo a validade do ordenamento, deixando, portanto, que ele se retire da exceção, a abandone ${ }^{6}$. Não é a exceção que se subtrai à regra, mas a regra que, suspendendo-se, dá lugar à exceção e somente desse modo se constitui como regra, mantendo-se em relação com aquela. ${ }^{7}$

A complexidade da exceção que define a soberania advém desses paradoxos e indeterminações.

Agamben, abalando noções tradicionais do estudo da teoria do estado, destaca que a soberania "não é, então, nem um conceito exclusivamente político, nem uma categoria exclusivamente jurídica, nem uma potência externa ao direito (Schmitt), nem a norma suprema do ordenamento jurídico (Kelsen): ela é a estrutura originária na qual o direito se refere à vida e a inclui em si através da própria suspensão." ${ }^{, 8}$ A soberania está dentro e fora do ordenamento, por isso não pode ser rotulada como apenas jurídica, ou apenas não jurídica. A decisão soberana marca um lugar de indistinção entre o exterior e o interior; o estado de exceção traça um limite - indefinido - entre o caos e a normalidade, a anomia e a ordem. O lugar da soberania é uma zona de indeterminação.

A exceção também não pode ser caracterizada como um fato ou uma situação de direito, mas sim um limiar de indiferença entre essas duas searas: "Não é um fato, porque é criado apenas pela suspensão da norma; mas, pela mesma razão, não é nem ao menos um caso jurídico, ainda que abra a possibilidade de vigência da lei."9 Desta passagem, resta compreensível ser o estado de exceção ilocalizável. Agamben enfatiza que "Quando nosso tempo tentou atribuir ao ilocalizável uma localização visível e permanente, o resultado foi o campo de concentração."10 Pois no campo de

${ }^{5}$ Citação de Carl Schmitt, referida em AGAMBEN, op. cit., p. 23.

6 “A relação de exceção é uma relação de bando. Aquele que foi banido não é, na verdade, simplesmente posto fora da lei e indiferente a esta, mas é abandonado por ela, ou seja, exposto e colocado em risco no limiar em que vida e direito, externo e interno, se confundem" (Ibidem, p. 36).

${ }^{7}$ Ibidem, p. 26.

${ }^{8}$ Ibidem, p. 35.

${ }^{9}$ Ibidem, p. 26.

${ }^{10}$ Ibidem, p. 27. 
concentração, o direito é suspenso, consistindo num espaço e num tempo fora do estado de direito.

Na exceção há indistinção entre estado de natureza e de direito. O estado de exceção "irrompeu seus confins espaço-temporais e, esparramando-se para fora deles, tende agora por toda parte a coincidir com o ordenamento normal, no qual tudo se torna assim novamente possível."11 Quando o estado de exceção se torna a regra, a insegurança instala-se, porque não se sabe o que está fora ou dentro do direito. Assim, qualquer conduta pode ser considerada transgressora.

Agamben conclui que o estado de exceção é um vazio de direito, uma zona anômica em que as distinções perdem sentido. Aproveita da reflexão de Carl Schmitt a observação de que esta zona de anomia é essencial para o direito, pois "somente porque a validade do direito positivo é suspensa no estado de exceção, ele pode definir o caso normal como âmbito da própria validade." ${ }^{12}$ A exceção é importante para a regra, pois define o espaço de validade da regra - o caso normal. Apenas porque existe a exceção é que a regra existe, tem sua validade confirmada. Nesse sentido é que Agamben afirma que a exceção é uma espécie de exclusão, pois o excluído não deixa de se relacionar com a norma, ainda que na forma de suspensão. Trata-se de uma singularidade que mesmo excluída da norma se relaciona com ela, pois a norma aplicase à exceção desaplicando-se.

A exceção soberana "é aquilo que não pode ser incluído no todo ao qual pertence e não pode pertencer a conjunto no qual está desde sempre incluído. O que emerge nesta figura-limite é a crise radical de toda possibilidade de distinguir com clareza entre pertencimento e inclusão, entre o que está fora e o que está dentro, entre exceção e norma." ${ }^{\prime 13}$ A exceção é algo impossível de se incluir na norma; ela só pode ser incluída, portanto, em uma situação de exceção, em que é incluída pela exclusão. E a decisão soberana está entre a exclusão e a inclusão.

\footnotetext{
${ }^{11}$ Ibidem, p. 44.

${ }^{12}$ Ibidem, p. 25.

${ }^{13}$ Ibidem, p. 32.
} 
Em "Estado de exceção", Agamben aprofunda a discussão do tema, e trata 1) da constatação de que o estado de exceção tem se tornado a regra ${ }^{14}$ e 2) da relação paradoxal entre direito e anomia.

O estado de exceção como estrutura em que o direito inclui a vida por meio de sua própria suspensão tem um significado biopolítico ${ }^{15}$. Esse significado aparece, por exemplo, no USA Patriot Act de 2001, pelo qual os talibãs capturados no Afeganistão não gozam do estatuto de prisioneiros de guerra nem de acusados segundo as leis norte-americanas. Anula-se o "estatuto jurídico do indivíduo, produzindo, dessa forma, um ser juridicamente inominável e inclassificável."16 Os viventes são objeto de uma

${ }^{14}$ Aqui há a referência à oitava tese de Walter Benjamin sobre o conceito de história: "A tradição dos oprimidos nos ensina que o 'estado de exceção' em que vivemos é na verdade a regra geral. Precisamos construir um conceito de história que corresponda a essa verdade. Nesse momento, percebemos que nossa tarefa é originar um verdadeiro estado de exceção; com isso, nossa posição ficará mais forte na luta contra o fascismo. Este se beneficia da circunstância de que seus adversários o enfrentam em nome do progresso, considerado como uma norma histórica" (AGAMBEN, Giorgio. Estado de exceção. Trad. Iraci D. Poleti. São Paulo: Boitempo, 2004, p. 90).

${ }^{15}$ Agamben aproveita os estudos de Michel Foucault sobre os mecanismos de normatização da vida na sociedade contemporânea. De acordo com Foucault, duas tecnologias de poder que se articulam nas sociedades modernas: a disciplina e a biopolítica. Nos séculos XVII e XVIII apareceu a técnica de poder disciplinar: "centrada no corpo, produz efeitos individualizantes, manipula o corpo como foco de forças que é preciso tornar úteis e dóceis ao mesmo tempo" (FOUCAULT, Michel. Em defesa da sociedade. Trad. Maria Ermantina Galvão. São Paulo: Martins Fontes, 2002, p. 297). Durante a segunda metade do século XVIII, surge uma outra tecnologia de poder, que não substitui a disciplina, e sim se articula com ela, e que se aplica à população - a biopolítica. Envolve processos aleatórios e coletivos, como natalidade, fecundidade, produção, longevidade, morbidade etc. Fenômeno fundamental foi o desenvolvimento desse poder sobre a vida, de gerência da vida. Seus mecanismos são medições, estatísticas, previsões, visando interferir/regular os processos biológicos do homem-espécie. O elemento que permite o controle tanto do corpo quanto dos acontecimentos aleatórios de uma multiplicidade biológica é a norma. Se na teoria clássica, o soberano tinha o direito de fazer morrer e deixar viver, no século XIX, o poder é de fazer viver (regulamentando como viver) e deixar morrer. Foucault ressalta que a transformação da vida humana em objeto de poder reduziu a vida ao seu componente puramente biológico, o que Agamben denomina de "vida nua". "Neste sentido, a contribuição mais importante de Agamben no interior do debate sobre as estruturas do biopoder consiste em mostrar como a vida nua vai progressivamente coincidindo com a integralidade do espaço político, no sentido de ela ser posta como a figura hegemônica da vida que pode aparecer no interior do espaço político. Isto implica necessariamente compreender qual a estrutura jurídica própria a um poder que reduz a vida à condição de mera vida biológica. É neste ponto que se articulam os livros 'Homo Sacer' e 'Estado de Exceção" (AGAMBEN, Giorgio. A política da profanação. Disponível em: <http://www.geocities.com/vladimirsafatle/vladi081.htm> Acesso em: 6 ago. 2007. Entrevista a Vladimir Safatle).

${ }^{16}$ AGAMBEN. Estado de exceção..., p. 14. 
dominação de fato, fora da lei ${ }^{17}$.

O estado de exceção é a figura de um quadro de suspensão da ordem jurídica em "casos extremos". "A segurança como paradigma de governo não nasce para instaurar a ordem, mas para governar a desordem. (...) Trata-se de criar zonas de desordem permanente que permitem intervenções constantes orientadas na direção que se julgar útil.",18

Essa criação de um estado de emergência (que nem sempre é declarado como tal) para solucionar conflitos e eliminar ameaças tornou-se prática contemporânea, paradigma dominante de governo, e não mais medida excepcional e provisória. Atualmente a lei convive com sua própria suspensão, o que transforma radicalmente o sentido e o caráter do Estado democrático, pois o estado de exceção situa-se em um espaço indefinido entre democracia e absolutismo ou totalitarismo.

Entre 1934 e 1948, a teoria do estado de exceção ganhou relevância, mas sob a forma de "ditadura constitucional". As medidas excepcionais justificar-se-iam para a defesa da constituição democrática. Mas torna-se embaçada a linha a partir da qual essa ditadura torna-se inconstitucional por derrubar a própria ordem constitucional.

Durante as guerras mundiais houve um incremento dos poderes do executivo, o que alterou os regimes democráticos. A abolição provisória da distinção entre os poderes legislativo, executivo e judiciário - uma vez que o executivo passa a legislar e gozar de plenos poderes num estado emergencial - torna-se prática duradoura de

17 Como nota Philip Golub, "Nos Estados Unidos, a amplitude do recuo democrático é espantosa. Através de um estado de exceção não-declarado, mas efetivo, o governo Bush procede à demolição sistemática da ordem constitucional. Governar por decretos secretos e decisões presidenciais arbitrárias tornou-se uma prática normal do Estado, como atestam as revelações cotidianas sobre a tortura, a existência de um arquipélago de prisões secretas e as operações não legais de espionagem interior. Agindo por trás de uma cortina de segredos, o Executivo norte-americano arrogou-se consideráveis poderes extra-jurídicos. Pisa nos tratados internacionais e empreende guerras preventivas; prende, tortura e mantém indefinidamente detido, sem julgamento, qualquer um que tenha sido identificado por decreto presidencial como um "combatente ilegal"; apóia-se na criação de um "sistema" judiciário paralelo e secreto, colocado sob o controle direto do Pentágono e da Casa Branca; em poucas palavras: atribui a si mesmo o poder de ultrapassar a ordem existente definida pelo direito internacional e nacional" (GOLUB, Philip S. Eclipse da democracia. Disponível em: <http://diplo.uol.com.br/2006-09,a1396> Acesso em: 6 ago. 2007).

${ }^{18}$ AGAMBEN. A política da profanação..., op. cit. 
governo, instalando um estado de exceção ${ }^{19}$.

O estado de exceção abre uma lacuna no ordenamento para garantir a existência da norma e sua aplicabilidade. O direito contém uma fratura preenchida pelo estado de exceção, que cria uma área em que se suspende a aplicação do direito sem excluí-lo. Deve-se perceber que

[...] o estado de exceção não é nem exterior nem interior ao ordenamento jurídico e o problema de sua definição diz respeito a um patamar, ou a uma zona de indiferença, em que dentro e fora não se excluem mas se indeterminam. A suspensão da norma não significa sua abolição e a zona de anomia por ela instaurada não é (ou, pelo menos, não pretende ser) destituída de relação com a ordem jurídica. ${ }^{20}$

O estado de exceção é uma zona de indecisão ou indiferença, "uma tentativa de incluir na ordem jurídica a própria exceção, criando uma zona de indiferenciação em que fato e direito coincidem." 21

O arquétipo do moderno estado de exceção pode ser considerado o instituto do direito romano denominado iustitium. Ao sinal de perigo para a República, o Senado emitia um senatus consultum ultimum requerendo que fosse tomada alguma medida necessária à salvação do Estado. Esse pedido baseava-se num decreto que declarava o tumultus (uma situação de emergência), e dava lugar, habitualmente, à proclamação de iustitium. O termo iustitium significa interrupção/suspensão do direito, a produção de um vazio jurídico. É a resposta à necessidade de romper o ordenamento para salvá-lo. O consultum pressupõe o tumultus e o tumultus é a única causa do iustitium. O iustitium não pode ser interpretado como ditadura, mas sim como um vazio e uma interrupção do direito, uma zona de anomia ${ }^{22}$. Esse espaço vazio de direito é essencial

${ }^{19}$ A constatação de que a maioria das leis brasileiras é de iniciativa do Poder Executivo e o excesso de medidas provisórias é marca evidente do fortalecimento do Executivo, trazendo, dentre outros efeitos, a insegurança de temas relevantes serem tratados por legislação emergencial.

${ }^{20}$ AGAMBEN. Estado de exceção..., p. 39.

${ }^{21}$ Ibidem, p. 42.

22 Explica Agamben que "Caso se quisesse, a qualquer preço, dar um nome a uma ação realizada em condições de anomia, seria possível dizer que aquele que age durante o iustitium não executa nem transgride, mas inexecuta o direito. Nesse sentido, suas ações são meros fatos cuja 
à ordem jurídica, e por isso o direito precisa manter-se em relação com a anomia.

O estado de exceção, seguindo essa origem, é um vazio jurídico relacionado com o ordenamento (na medida em que o suspende), para lidar com situações emergenciais ou ameaçadoras (ainda que não se saiba para quem).

Carl Schmitt elaborou rigorosa tentativa de construir uma teoria do estado de exceção, por isso suas teses foram analisadas por Agamben ${ }^{23}$.

No livro "A ditadura", Carl Schmitt descreveu o contexto em que se insere o estado de exceção. Havia a "ditadura comissária”, que visava a defender ou a restaurar a ordem constitucional existente, e a "ditadura soberana", que, como figura de exceção, destruiria essa ordem.

Schmitt sabia que o estado de exceção, ao suspender a ordem jurídica, escapava à consideração jurídica, embora se relacionasse com a ordem. $\mathrm{O}$ estado de exceção não seria um caos, mas uma ordem, ainda que não jurídica. A teoria schmittiana articulou, então, estado de exceção e ordem jurídica, com a inscrição no direito de algo exterior a ele.

Em "A ditadura", essa inscrição é operada pela distinção entre (i) normas do direito e de realização do direito, na ditadura comissária, e (ii) poder constituinte e poder constituído, na ditadura soberana. Na ditadura comissária, a Constituição é suspensa quanto à sua aplicação, embora permaneça em vigor. Na ditadura soberana,

apreciação, uma vez caduco o iustitium, não são absolutamente passíveis de decisão e a definição de sua natureza - executiva ou transgressiva e, no limite, humana, bestial ou divina - está fora do âmbito do direito" (Ibidem, p. 78).

${ }^{23}$ Agamben analisa tanto as contribuições de Carl Schmitt quanto de Walter Benjamin. No capítulo 4 de "Estado de exceção", trata-se do debate entre Schmitt e Benjamin (dois gigantes) sobre o estado de exceção (um vazio). No ensaio "Crítica da violência: crítica do poder", Benjamin afirma a possibilidade de uma violência (pura) fora do direito, que não põe nem conserva o direito, e sim o depõe. A teoria schmittiana da soberania pode ser tomada como resposta ao ensaio benjaminiano. Schmitt traz a violência pura e anômica para o contexto jurídico: na medida em que no estado de exceção a violência se inclui no direito por sua exclusão, ela não existe absolutamente fora do direito. Responde à violência pura com a violência soberana que suspende o direito. Situar a soberania, como decisão extrema, nem no exterior nem no interior do direito é uma tentativa schmittiana de neutralizar a violência pura e garantir a relação entre a anomia e o direito. A discussão entre Benjamin e Schmitt se dá num espaço de anomia que deve se relacionar com o direito e também se libertar dessa relação, ou seja, em que se questiona a relação entre violência e direito. Schmitt tenta inscrever a violência no contexto jurídico e Benjamin procura assegurar à violência pura uma existência fora do direito. 
suspende-se a Constituição vigente e propicia-se a imposição de uma nova Constituição.

Em "Teologia política", o operador da inscrição do estado de exceção na ordem jurídica é a distinção entre a norma e a decisão. A decisão refere-se à anulação da norma, incluindo um espaço que não está fora nem dentro da ordem jurídica. Nesse sentido é que a teoria do estado de exceção é doutrina da soberania, considerando que soberano é aquele que decide sobre o estado de exceção.

A distinção entre normas do direito e de realização do direito, na ditadura comissária, mostra que o momento da aplicação da norma é autônomo em relação à norma em si; portanto, representa "um estado da lei em que esta não se aplica, mas permanece em vigor" ${ }^{24}$. A distinção entre norma e decisão, por sua vez, mostra que a decisão sobre o estado de exceção introduz no direito uma zona de anomia para tornar possível a aplicação da norma. O estado de exceção intensifica a oposição entre a norma e a sua realização; "o mínimo de vigência formal coincide com o máximo de aplicação real e vice-versa.",25

Na mesma esteira, Agamben cita a conferência de Jacques Derrida intitulada "Força de lei: o fundamento místico da autoridade" $" 26$ Tradicionalmente distingue-se

${ }^{24}$ Ibidem, p. 58.

${ }^{25}$ Ibidem, loc. cit..

${ }^{26}$ Esta conferência encontra-se publicada: DERRIDA, Jacques. Force de loi: le "fondement mystique de l'autorité". Desconstruction and the possibility of justice. Cardozo law Review, v. 11, n. 5-6, p. 919-1045, jul-aug. 1990. (DERRIDA, Jacques. Força de lei: o "fundamento místico da autoridade”. Trad. Leyla Perrone-Moisés. São Paulo: WMF Martins Fontes, 2007). O principal tema da conferência pode ser considerado a distinção entre direito e justiça. Derrida relembra um pensamento de Pascal em que se afirma que o mais justo e o mais forte devem ser seguidos. O justo deve ser seguido porque isso é justo, e o mais forte deve ser seguido porque isso é necessário. O ideal, então, é unir justiça e força: fazer com que o justo seja forte e o forte seja justo. Mas frente à impossibilidade de fazer forte o justo, Pascal ressalta que fizeram com que o forte fosse justo, isto é, foi forjada uma justiça para legitimar a força. Então Pascal recorre a uma expressão de Montaigne: as leis se mantêm em crédito não porque são justas, mas porque são leis, ou seja, porque têm um "fundamento místico de autoridade". Torna-se evidente a distinção entre direito e justiça. O fundamento das leis, a razão de sua autoridade é o crédito que se lhes concede a crença, algo místico. O direito é construído em ficções para fundar a verdade de sua justiça, pois não encontra fundamento fora de si mesmo. O surgimento da justiça e do direito implica uma força performadora (apelando à crença): o direito não surge para manter uma força ou servir a um poder social. "Ora, a operação de fundar, inaugurar, justificar o direito, fazer a lei, consistiria num golpe de força, numa violência performativa e portanto interpretativa que, nela mesma, não é nem justa nem injusta, e que nenhuma 
"a eficácia da lei, que decorre de modo absoluto de todo ato legislativo válido e consiste na produção de efeitos jurídicos, e força de lei que, ao contrário, é um conceito relativo que expressa a posição da lei ou dos atos do ordenamento jurídico, dotados de força superior à lei (como é o caso da constituição) ou de força inferior a ela (os decretos e regulamentos promulgados pelo executivo)."27 Contudo, em sentido técnico, "força da lei" refere-se aos decretos promulgados pelo executivo. Assim, medidas que não são formalmente leis adquirem sua força.

No estado de exceção, isola-se a força da lei em relação à lei. O estado de exceção "define 'um estado da lei' em que, de um lado, a norma está em vigor, mas não se aplica (não tem 'força') e em que, de outro lado, atos que não têm valor de lei adquirem sua 'força'. (...) O estado de exceção é um espaço anômico onde o que está em jogo é uma força de lei sem lei (que deveria, portanto, ser escrita: força de \ei)." "28 Assim, Agamben consegue expressar graficamente a situação verificada no estado de exceção.

Percebe-se que "o estado de exceção marca um patamar onde lógica e práxis se indeterminam e onde uma pura violência sem logos pretende realizar um enunciado sem nenhuma referência real." 29 $\mathrm{Na}$ força pura a norma se aplica desaplicando-se. A força de lei sem lei permite pensar em algo místico que significa um momento em que o direito se relaciona com a sua ausência.

O direito necessita dessa zona anômica de suspensão para existir; a relação entre norma e realidade implica a suspensão da norma. Essa zona "coincide com uma figura extrema e espectral do direito, em que ele se divide em uma pura vigência sem

justiça, nenhum direito prévio e anteriormente fundador, nenhuma fundação preexistente, por definição, poderia nem garantir nem contradizer ou invalidar" (DERRIDA. Força de lei ..., p. 24). O discurso encontra seu limite no seu próprio poder performativo, no místico. A instauração da lei apóiase nela mesma, numa violência que não é nem justa nem injusta no momento fundador. Surge o direito porque é autoridade, não porque é justo. Assim, o direito é desconstrutível "porque ele é fundado, isto é, construído sobre camadas textuais interpretáveis e transformáveis (...) ou porque seu fundamento último, por definição, não é fundado" (Ibidem, p. 26). O que não é um mal, pois pode proporcionar a chance de progresso histórico.

\footnotetext{
${ }^{27}$ AGAMBEN. Estado de exceção..., p. 60.

${ }^{28}$ Ibidem, p. 61.

${ }^{29}$ Ibidem, p. 63.
} 
aplicação (a forma de lei) e em uma aplicação sem vigência: a força de lè̀." ${ }^{30}$ Assim, a estrutura do estado de exceção mostra-se complexa. A violência pura, que interrompe e depõe o direito ${ }^{31}$, não é capturada e inserida na ordem jurídica, mas sim o que resulta do estado de exceção é pressuposto ao direito.

É importante explicar também que o sistema jurídico do Ocidente apresenta-se como uma estrutura formada por dois elementos: a potestas (elemento normativo e jurídico em sentido estrito) e a auctoritas ${ }^{32}$ (elemento anômico e metajurídico). "O elemento normativo necessita do elemento anômico para poder ser aplicado, mas, por outro lado, a auctoritas só pode se afirmar numa relação de validação ou de suspensão da potestas." 33

O estado de exceção articula esses dois aspectos, sendo uma zona fronteiriça e embaçada entre anomia e nomos, vida e direito, auctoritas e potestas. Ele baseia-se na ficção de que a anomia relaciona-se com o direito. Enquanto os dois elementos se vinculam mantendo-se distintos, a dialética funciona. Já na situação de exceção, em que não se distingue direito e anomia, há insegurança e o funcionamento de uma

${ }^{30}$ Ibidem, p. 93.

${ }^{31}$ Walter Benjamin expôs o nexo entre violência e direito, o que o torna importante nos estudos sobre a soberania. Esse nexo oscila entre violência que põe e que conserva o direito. Para romper com essa oscilação dialética, há a necessidade da figura da violência divina, que não põe nem conserva o direito, mas o depõe. Agamben refere-se à violência soberana, que não conserva nem põe o direito (mas que não se confunde com a divina), mas sim o conserva suspendendo-o e o põe excetuando-se dele. A violência soberana é exercitada no estado de exceção, e inaugura uma zona de indistinções (AGAMBEN. Homo sacer..., p. 71-75).

${ }^{32}$ A já referida prerrogativa do Senado de suspender o direito por meio do senatus consultum ultimum e a conseqüente proclamação do iustitium era auctoritas. No âmbito público, a auctoritas designa a referida prerrogativa especial do Senado. Exprime a ratificação ou validação, pelo Senado, das decisões populares. No caso extremo, a auctoritas é "um poder que suspende ou reativa o direito, mas não tem vigência formal como direito" (AGAMBEN. Estado de exceção..., p. 121). A auctoritas (mera escrita que vive) é o que resta do direito suspenso. A auctoritas só é compreensível a partir do direito romano do período do principado. Esse poder de legitimar e garantir a vida política era imediatamente inerente à pessoa do princeps. Assim, o direito é imanente à vida. A autoridade deriva (quase magicamente) da pessoa e baseia-se no consenso e no reconhecimento de sua superioridade (refere-se, aqui, ao poder carismático definido por Weber). Contudo, Agamben nota que o poder deriva da suspensão do direito, do estado de exceção. De todo modo, o que se percebe é que o direito coincide com a vida. Nesse sentido, a "norma pode ser aplicada ao caso normal e pode ser suspensa sem anular inteiramente a ordem jurídica porque, sob a forma da auctoritas ou da decisão soberana, ela se refere imediatamente à vida e dela deriva" (Ibidem, p. 129-130).

${ }^{33}$ Ibidem, p. 130. 
máquina letal, absorvendo a vida e exercendo sobre ela uma violência nua.

O estado de exceção justamente "é aquela figura que inscreve a anomia no nomos, suspende a norma para que prevaleça a pura decisão, fazendo com que o poder puro e simples (aquele sem mediações das garantias do Estado de Direito) pertença ao direito, mesmo dele, 'em regra', estando fora."34

Agamben mostra que o poder em nosso tempo contém em seu centro o estado de exceção, "um espaço vazio, onde uma ação humana sem relação com o direito está diante de uma norma sem relação com a vida." 35 E essa máquina é eficaz, funciona. "O aspecto normativo do direito pode ser, assim, impunemente eliminado e contestado por uma violência governamental que, ao ignorar no âmbito externo o direito internacional e produzir no âmbito interno um estado de exceção permanente, pretende, no entanto, ainda aplicar o direito." 36

O estado de exceção é o ponto de maior tensão entre as forças que instituem/põem e as que desativam/depõem, e também o ponto em que as forças podem se tornar indiscerníveis. É necessário, então, tentar interromper essa máquina, separando as duas forças. Cabe desmascarar a fictícia articulação entre vida e direito. No corte do nexo entre violência e direito está o espaço da ação política. Nesse espaço, é possível pensar num outro uso do direito. Haverá, então, um direito puro.

É possível um direito após a deposição de seu vínculo com a violência e o poder: um direito sem força nem aplicação. "O que abre uma passagem para justiça não é a anulação, mas a desativação e a inatividade do direito - ou seja, um outro uso dele. Precisamente o que a força de lei - que mantém o direito em funcionamento além de sua suspensão formal - pretende impedir."37 O que leva à justiça passa pela desativação e inatividade do direito, pelo brincar com o direito para libertá-lo, empregá-lo em novo uso.

\footnotetext{
${ }^{34}$ FONSECA, Ricardo Marcelo. Resenha - AGAMBEN, Giorgio Estado de exceção. Revista da Faculdade de Direito da Universidade Federal do Paraná, Curitiba, n. 41, p. 172, 2005.

35 AGAMBEN. Estado de exceção..., p. 131.

${ }^{36}$ Ibidem, loc.cit.
} 


\section{PARALELO CONCLUSIVO ENTRE TEORIA E PRÁTICA: UM ABISMO?}

Apenas da leitura dos julgados e da compreensão do sentido do estado de exceção é possível perceber que houve uma aplicação distorcida da teoria. Apesar dessa evidência, cabem, ainda, algumas observações sobre os trechos já destacados do voto do Ministro Eros Grau.

É verdade que não só o Supremo Tribunal Federal, mas todos os órgãos jurisdicionais não podem se limitar à prática de mero exercício de subsunção. Todavia, ir além da subsunção requer coerência, responsabilidade e cuidado.

Pode-se dizer que a regra é a solução mais adequada para a maior parte dos casos. Freqüentemente encontra-se o operador diante de "problemas jurídicos nem sempre complexos, onde a simples incidência ou aplicação de regras infraconstitucionais, mediante aplicação da velha lógica da subsunção, seria suficiente para uma adequada resposta jurídica."38

Mas a lei não consegue dar conta de toda a realidade, e é nas falhas decorrentes dessa generalidade (e ao se deparar com situações peculiares não previstas anteriormente) que se pode agregar questões valorativas à interpretação da lei. "Nessa hipótese, o aplicador deve analisar a finalidade da regra, e somente a partir de uma ponderação de todas as circunstâncias do caso pode decidir que elemento de fato tem prioridade para definir a finalidade normativa."39

Assim, diante da existência de uma regra, não se pode simplesmente aplicá-la sem mais. Na aplicação das regras deve-se considerar seu impacto na realidade. Isso significa afirmar que a validade da norma é aferida não apenas no plano abstrato, mas também perquirindo o resultado decorrente da subsunção, do processo interpretativo.

${ }^{37}$ Ibidem, p. 98.

${ }^{38}$ SCHIER, Paulo Ricardo. Novos desafios da filtragem constitucional no momento do neoconstitucionalismo. A \& C Revista de Direito Administrativo e Constitucional, Belo Horizonte, a. 5, n. 20, p. 162-163, abr./jun. 2005.

39 ÁVILA, Humberto. Teoria dos princípios: da definição à aplicação dos princípios jurídicos. 4. ed. São Paulo: Malheiros, 2005, p. 49. 
A superação histórica do jusnaturalismo e o fracasso do positivismo abriram o campo para o pós-positivismo, “designação provisória e genérica de um ideário difuso, no qual se incluem o resgate dos valores, a distinção qualitativa entre princípios e regras, a centralidade dos direitos fundamentais e a reaproximação entre o Direito e a Ética." 40

Para tentar alcançar a justiça ${ }^{41}$, realizar valores e ter-se um resultado razoável, o produto da subsunção deve ser submetido aos princípios, ou seja, a análise do caso concreto se faz a partir da regra e de todas as outras normas e valores incidentes sobre o caso. Não se propõe abandonar o método subsuntivo e os elementos tradicionais da hermenêutica, e sim afirmar a necessidade de sua complementação.

Admite-se que "há situações em que uma regra, perfeitamente válida em abstrato, poderá gerar uma inconstitucionalidade ao incidir em determinado ambiente ou, ainda, há hipóteses em que a adoção do comportamento descrito pela regra violará gravemente o próprio fim que ela busca alcançar." ${ }^{„ 2}$ Nesses casos, há uma situação de ruptura, "em que a aplicação da regra cria uma grave incompatibilidade com o sistema constitucional e, por isso, se admitirá a ponderação dos bens ou interesses que ela

${ }^{40}$ BARROSO, Luís Roberto; BARCELLOS, Ana Paula de. O começo da história. A nova interpretação constitucional e o papel dos princípios no direito brasileiro. Interesse Público, Porto Alegre, v. 5, n. 19, p. 79, maio/jun. 2003.

${ }^{41}$ Nesse aspecto, cabe mencionar que a impossibilidade da realização presente e plena da justiça é realçada na obra de Jacques Derrida. Segundo o autor, a justiça, sempre algo que está por vir, é a experiência do que não se pode experimentar, do impossível. Pode-se ter certeza de que o direito foi respeitado, mas não de que a justiça foi feita. Isso porque o direito não é justiça; a decisão entre o justo e o injusto não se garante por uma regra. Tarefa difícil é conciliar direito e justiça, pois se trata de encaixar uma singularidade numa generalidade. Há uma "distinção entre a justiça e o direito, uma distinção difícil e instável entre, de um lado, a justiça (infinita, incalculável, rebelde às regras, estranha à simetria, heterogênea e heterotrópica) e, de outro lado, o exercício da justiça como direito, legitimidade ou legalidade, dispositivo estabilizável, estatutário e calculável, sistema de prescrições regulamentadas e codificadas" (DERRIDA. Força de lei..., p. 41). E seria simples se a distinção entre justiça e direito fosse verdadeiramente evidente ou inequívoca. "Mas acontece que o direito pretende exercer-se em nome da justiça, e que a justiça exige ser instalada num direito que deve ser posto em ação" (Ibid., p. 42-43). Por isso, Derrida anuncia aporias (ou travessias de não-caminhos) nas quais a desconstrução encontra seu lugar, deslocando-se entre o direito e a justiça, o descontrutível e o indesconstrutível, na tentativa dessa experimentação do que não se pode experimentar.

${ }^{42}$ BARROSO; BARCELLOS, op. cit., p. 60. 
tutela de modo até mesmo a permitir a sua não aplicação em um caso concreto."43

Considerando esse cenário, Humberto Ávila mostra que "A ponderação ${ }^{44}$ diz respeito tanto aos princípios quanto às regras, na medida em que qualquer norma possui um caráter provisório que poderá ser ultrapassado por razões havidas como mais relevantes pelo aplicador diante do caso concreto." ${ }^{, 45}$ Em certos casos,

[...] a conseqüência estabelecida prima facie pela norma pode deixar de ser aplicada em face de razões substanciais consideradas pelo aplicador, mediante condizente fundamentação, como superiores àquelas que justificam a própria regra. Ou se examina a razão que fundamenta a própria regra (rule's purpose) para compreender, restringindo ou ampliando, o conteúdo de sentido da hipótese normativa, ou se recorre a outras razões, baseadas em outras normas, para justificar o descumprimento daquela regra (overruling). Essas considerações bastam para demonstrar que não é adequado afirmar que as regras 'possuem' um modo absoluto 'tudo ou nada' de aplicação. Também as normas que aparentam indicar um modo incondicional de aplicação podem ser objeto de superação por razões não imaginadas pelo legislador para os casos normais. A consideração de circunstâncias concretas e individuais não diz respeito à estrutura das normas, mas à sua aplicação; tanto os princípios como as regras podem envolver a consideração a aspectos específicos, abstratamente desconsiderados. $^{46}$

Ou seja, somente após a interpretação é que se pode verificar se uma norma implementa uma conseqüência predeterminada. Assim, haverá casos em que as regras não serão aplicadas, apesar de suas condições terem sido satisfeitas. Nesses casos, as razões que justificam a regra são canceladas por outras consideradas superiores.

43 BARCELLOS, Ana Paula de. Alguns parâmetros normativos para a ponderação constitucional. In: BARROSO, Luis Roberto (Org.). A nova interpretação constitucional. Rio de Janeiro: Renovar, 2003. p. 92.

${ }^{44}$ A técnica da ponderação surge como um raciocínio diverso capaz de sintetizar os diversos elementos normativos incidentes em um caso concreto. A ponderação desenvolve-se em três etapas: 1) detecção, no sistema, das normas relevantes para a solução do caso; 2) exame das circunstâncias concretas do caso e de sua interação com os elementos normativos; 3) apuração dos pesos que devem ser atribuídos aos elementos em disputa, e decisão do grupo de normas que deve predominar, tendo por baliza a proporcionalidade ou razoabilidade. Tudo isso envolve apreciações subjetivas, que devem ser controladas. BARROSO; BARCELLOS, op. cit., p. 62-63.

45 ÁVILA, op. cit., p. 50. Assim, o autor critica o critério que distingue regras e princípios considerando o conflito normativo. Segundo a distinção tradicionalmente realizada, o conflito entre regras é resolvido com a declaração de invalidade de uma delas ou com a criação de uma exceção, enquanto o conflito entre princípios é decidido numa dimensão de peso, utilizando-se a técnica da ponderação.

${ }^{46}$ Ibidem, p. 38-39. 
Introduz-se o pensamento casuístico ${ }^{47}$ para flexibilizar o sistema, permitindo a adequação das regras à realidade. Somente a partir da interpretação concreta da lei, pode-se reconhecer os limites precisos e adequados da tutela jurídica. O temperamento na interpretação da lei possibilita resultados mais adequados, como explica Maria Cláudia Cachapuz: "Há que se exigir, portanto, na análise de cada caso, um temperamento de interpretação da lei específica. Não de forma a causar um sentimento de insegurança jurídica. Mas sim, pela busca de uma realização concreta dos ideais jurídicos" ${ }^{48}$.

Segundo Humberto Ávila, na ponderação entre regras deve-se considerar, por um lado, as razões que justificam a obediência à regra, tais como segurança jurídica e previsibilidade do direito, e, por outro, as razões que justificam o abandono da regra. Assim, opera-se uma ponderação nos casos em que há uma discrepância entre o que fundamenta a regra e o que a faz incidir. Nesse sopesar, espera-se encontrar uma resposta adequada, considerando os valores que informam o sistema jurídico brasileiro.

A situação da integração irregular de determinada faixa de terras em outro Município, em abstrato, configura inconstitucionalidade, mas essa declaração de inconstitucionalidade com efeitos retroativos pode causar forte abalo para os habitantes do local. Nesse caso, os danos gerados com a aplicação da norma podem ser maiores que aqueles causados pela sua não aplicação. Também o seqüestro de verbas públicas para pagar um precatório específico fora da situação de desobediência da ordem cronológica configura-se indevido. Entretanto, não possibilitar o pagamento, que custeará o tratamento médico essencial ao respeito à dignidade da credora, é mais ofensivo à ordem constitucional, concluíram os Ministros. Apresentam-se, então, peculiaridades que destoam da regra geral, e critérios de equiidade e justiça podem levar ao afastamento da regra pela sua inconstitucionalidade no caso concreto. Assim,

\footnotetext{
${ }^{47}$ A respeito do pensamento tópico, ver, especialmente: VIEHWEG, Theodor. Tópica y jurisprudência. Madrid: Taurus, 1964.

${ }^{48}$ CACHAPUZ, Maria Cláudia. Bem de família: uma análise contemporânea. Revista dos Tribunais, São Paulo, a. 88, v. 770, p. 51, dez. 1999.
} 
o intérprete caracterizará o caso como excepcional (o que difere muito de caracterizar um estado de exceção) e deixará de aplicar a regra. Mas como regras devem ser obedecidas, a consideração de aspectos concretos e individuais pede uma fundamentação muito consistente ${ }^{49}$.

Pode-se pensar, então, que a fundamentação mais coerente para a decisão dos casos analisados pelo Supremo Tribunal Federal é a criação de exceções por meio da ponderação (com a possibilidade de afastamento de uma regra para atender a outro interesse) e a consideração dos resultados causados pela aplicação das normas.

Nas situações examinadas, foi realizado, em verdade, um sopesamento entre a regra que permite o seqüestro de verbas públicas apenas em caso de desobediência à ordem de pagamento dos precatórios, e a específica situação da credora, portadora de doença grave com necessidade de recursos para custear seu tratamento médico. Também no julgamento da lei estadual sobre incorporação de terras a Município houve ponderação entre o valor da segurança jurídica e os efeitos da declaração de inconstitucionalidade com efeitos ex tunc. Nesse balanceamento, prevaleceu a modulação dos efeitos da declaração de inconstitucionalidade ${ }^{50}$.

Teve razão o Ministro Eros Grau ao explicar que não se pode decidir com base apenas num juízo de subsunção frente a casos complexos, mas nem por isso se pode afirmar que uma situação que foge à regra geral configura um estado de exceção, no

49 Segundo BARROSO e BARCELLOS, “O controle de legitimidade das decisões obtidas mediante ponderação tem sido feito através do exame da argumentação desenvolvida" (BARROSO; BARCELLOS, op. cit., p. 64). Existem três parâmetros elementares para o controle da argumentação: 1) a argumentação deve apresentar fundamentos jurídicos, ainda que implícitos, preferindo-se a solução que se apoiar em maior número de normas jurídicas; 2) possibilidade de universalizar os critérios adotados pela decisão, ou seja, a possibilidade de os critérios empregados para solucionar um caso serem transformados em regra geral para casos semelhantes; 3) percorrer o caminho ditado pelos princípios específicos da interpretação constitucional (supremacia da Constituição, presunção de constitucionalidade das leis e atos do Poder Público, interpretação conforme a Constituição, unidade hierárquico-normativa da Constituição, razoabilidade e efetividade) para realizar o máximo possível dos princípios materiais (fundamentais, gerais e setoriais). O raciocínio deverá ser logicamente demonstrado.

${ }^{50}$ Lei federal no 9.868/99: “Art. 27 - O STF nos dois casos analisados, em uma interpretação mais extrema, mas não sem sentido, acabou por criar pequenos campos de concentração, pois determinou um espaço em que o direito vigente não vale, e sim apenas a decisão, a pura força. $\mathrm{O}$ campo é a localização e a realização do Estado de exceção." 
sentido da teoria de Agamben. É lícito concluir que a Corte poderia ter obtido as mesmas conclusões mediante uma fundamentação mais coerente.

As situações de fato trazidas nos autos foram consideradas exceções não previstas pelo direito positivo. Exceção é um “desvio da regra geral (...) aquilo que se exclui da regra" ${ }^{, 51}$. Nesse sentido, concorda-se que as situações analisadas pelo Supremo Tribunal Federal são excepcionais, visto não poderem ser aplicadas as regras sem gerar consequiências gravosas. Todavia, não é pelo fato de serem exceções que se pode concluir haver um estado de exceção. A exceção que define o estado de exceção tem outro sentido, como já apontado, sendo zona de indeterminação entre direito e anomia, norma e vida, uma exclusão inclusiva.

Já por essa constatação de não-correspondência entre uma exceção à regra e o sentido de exceção dos estudos de Agamben - e a equivocada correspondência alicerça todo o voto do Ministro Eros Grau - percebe-se a inadequação de suscitar as obras "Homo Sacer - poder soberano e vida nua" e "Estado de exceção", tendo em vista que tratam de planos distintos de argumentação. Entretanto, continue-se a análise dos demais trechos dos votos.

Com razão explicou o Ministro Eros Grau, citando Agamben, que "O estado de exceção é uma zona de indiferença entre o caos e o estado da normalidade". Contudo, ao contrário do que afirmou, essa zona de indiferença não é capturada pela norma, pois no estado de exceção a norma é suspensa.

Como anteriormente explanado, está correto, conforme o estudo de Agamben, constatar que "não é a exceção que se subtrai à norma, mas ela que, suspendendo-se, dá lugar à exceção - apenas desse modo ela se constitui como regra, mantendo-se em relação com a exceção". Todavia, o que se percebeu no voto foi o oposto: a subtração de uma singularidade da incidência de uma norma, e não a norma que se deixou suspender. Os casos analisados pelo Supremo Tribunal Federal eram realidades fáticas singulares; não foram criadas pela suspensão da norma, não são zonas de

${ }^{51}$ FERREIRA, Aurélio Buarque de Holanda. Novo dicionário da língua portuguesa. Rio de Janeiro: Nova Fronteira, 1975, p. 595. 
indeterminação. Ao invés de se caracterizarem como um vazio de direito, os casos foram preenchidos por direito - embora não aquele derivado das regras específicas afastadas. As situações foram trabalhadas dentro do direito vigente. A exceção, ao contrário, transcende o próprio direito, pois representa a suspensão do ordenamento. $\mathrm{O}$ direito de exceção não é direito, e sim puro poder. Na sua força pura, a norma aplicase desaplicando-se.

No voto, afirmou-se que ao Supremo Tribunal Federal, "sempre que necessário, incumbe decidir regulando também essas situações de exceção. Ao fazê-lo, não se afasta do ordenamento, eis que aplica a norma à exceção desaplicando-a, isto é, retirando-a da exceção". Contudo, tem-se que regular as situações de exceção é em si uma impossibilidade, pois se trata de preencher com direito algo que se caracteriza como vazio jurídico. Ainda, não se trata de retirar a norma da exceção, mas sim de uma relação de abandono, de exposição da vida.

Ressalte-se que soberano, para Carl Schmitt, é aquele que decide sobre o estado de exceção. A decisão soberana, para Agamben, é aquela que está entre a exclusão e a inclusão, num ilocalizável. Ao enunciar que as situações analisadas estão excluídas da norma (e, com isso, simultaneamente, afirmar o âmbito de validade das regras), o Supremo Tribunal Federal proferiu uma decisão soberana. Ao observar que compete à Corte decidir as situações de exceção, quando e como aplicar as normas constitucionais, identificar o que está dentro e fora e atribuir-lhes significado, concluise pelo reconhecimento da soberania ao STF (ou pelo chamamento para si do poder soberano). Nesse sentido, cabe questionar, por exemplo, se os Ministros estão legitimados para tomar essa decisão sobre a exceção ou trata-se de questão política; e se cabe ao STF decidir as situações de exceção, também os demais órgãos do Judiciário são competentes para tanto?

Percebe-se que o STF exerceu auctoritas (poder que suspende ou reativa o direito, mas não tem vigência formal como direito) quando detinha apenas a potestas (poder de aplicar o direito). Ao reunirem-se o elemento anômico e o elemento normativo em uma só pessoa/órgão, formou-se, nos casos analisados, uma máquina 
perigosa. Reuniu-se na Corte tanto a ordem quanto o caos, e assim foi absorvida a realidade e proferida qualquer decisão, pois decorrente de um puro poder. Nesse sentido, o STF, em uma interpretação extrema, mas não sem sentido, acabou por criar pequenos campos de concentração, na medida em que determinou em duas oportunidades um espaço em que o direito vigente não vale, e sim apenas a decisão, a pura força.

Afirmou-se que o estado de exceção gera insegurança por tornar indiscerníveis estado de natureza e estado de direito. Com as decisões analisadas, o STF acabou por aprofundar essa insegurança, pois se constata a ausência de critério para balizar a decretação de uma situação como excepcional. Assim, um caso concreto será uma exceção se o STF declará-la como tal e, nessa hipótese, o direito será suspenso, dando lugar a um puro poder. E mais insegurança ainda se sente quando a exceção acaba se tornando a regra, confirmando a teoria de Agamben.

Não se pode categoricamente afirmar que no Brasil vige um estado de exceção, permanente e total. Tal afirmação seria simples, mas carente de embasamento teórico e fático. Pelo significado e pelas repercussões do estado de exceção, cabe um alerta para o perigo de se declarar o estado de exceção e suspender o direito, ainda mais por um tribunal, que não detém soberania. O manejo da idéia de estado de exceção merece muito cuidado.

Observe-se que as decisões e votos ora analisados não foram objeto de debates e nem tiveram a merecida repercussão, embora caracterizem um problema teórico e uma práxis bastante inquietantes. Ao se evocar fora do seu contexto e significado a teoria do estado de exceção, deturpa-se a teoria e produzem-se equívocos. Reforce-se que o equívoco serviu de base para diferentes julgados, sobre temas diversos, e pode fundamentar decisões que estão por vir, formando uma cadeia grave de distorções e insegurança, e de deslocamento de soberania $^{52}$.

${ }^{52}$ Atualmente percebe-se uma politização da justiça, com a transferência para o Poder Judiciário de muitas questões que deveriam ser articuladas na esfera pública. Em interessante texto sobre o tema, a explicação de Chantal Mouffe: “(...) in current democratic societies this agonistic dimension has been steadily disappearing and that this explains why the juridical sphere has now 
Ao final desta breve análise, pode-se concluir que houve um abismo entre teoria e prática? Em verdade, há sempre esse abismo. O que se tentou, nas decisões analisadas, foi construir uma ponte, o que é realmente o exigido dos juristas. Contudo, a ponte construída não tinha condições de unir os dois mundos, pois se tratam de medidas diferentes.

De todo modo, resta a observação de que os estudos de Agamben estão se disseminando em solo brasileiro, o que é bastante frutífero para (re)pensar o direito e o Estado, desacomodando mitos e dogmas jurídicos, chacoalhando os juristas e alertando para situações-limite que ou são escondidas dos olhos, ou são publicamente expostas sob máscaras, ou que simplesmente não se deseja ver, mas que devem ser enfrentadas com responsabilidade.

\section{REFERÊNCIAS}

AGAMBEN, Giorgio. A política $d a$ profanação. Disponível em: <http://www.geocities.com/vladimirsafatle/vladi081.htm> Acesso em: 6 ago. 2007. Entrevista a Vladimir Safatle.

Estado de exceção. Trad. Iraci D. Poleti. São Paulo: Boitempo, 2004.

. Homo Sacer - O poder soberano e a vida nua. Trad. Henrique Burgo. Belo Horizonte: UFMG, 2004.

ÁVILA, Humberto. Teoria dos princípios: da definição à aplicação dos princípios jurídicos. 4. ed. São Paulo: Malheiros, 2005.

become the central terrain where social conflicts can find a form of expression. Today, because of the lack of democratic political public spaces where the agonistic confrontation can take place, I is increasingly the legal system which is seen as being responsible for organizing human coexistence and for regulating social relations. Given the growing impossibility of envisaging the problems of society in a political way, there is a marked tendency to privilege the juridical terrain and to expect the law to provide solutions for all types of conflicts" (MOUFFE, Chantal. The political, the moral and the juridical. Texto ainda não publicado, gentilmente cedido pela autora para estudos na Pós Graduação em Direito da UFPR, no primeiro semestre de 2007). 
BARCELLOS, Ana Paula de. Alguns parâmetros normativos para a ponderação constitucional. In: BARROSO, Luis Roberto (Org.). A nova interpretação constitucional. Rio de Janeiro: Renovar, 2003.

BARROSO, Luís Roberto; BARCELlOS, Ana Paula de. O começo da história. A nova interpretação constitucional e o papel dos princípios no direito brasileiro. Interesse Público, Porto Alegre, v. 5, n. 19, p. 51-80, maio/jun. 2003.

CACHAPUZ, Maria Cláudia. Bem de família: uma análise contemporânea. Revista dos Tribunais, São Paulo, a. 88, v. 770, p. 23-52, dez. 1999.

CHUEIRI, Vera Karam de. Agamben e o estado de exceção como zona de indeterminação entre o político e o jurídico. In: FONSECA, Ricardo Marcelo (Org.). Crítica da modernidade: diálogos com o direito. Florianópolis: Boiteux, 2005. p. 93107.

Nas trilhas de Carl Schmitt (ou nas teias de Kafka): soberania, poder constituinte e democracia (radical). In: FONSECA, Ricardo Marcelo (Org.). Repensando a teoria do Estado. Belo Horizonte: Fórum, 2004. p. 347-377.

DERRIDA, Jacques. Força de lei: o "fundamento místico da autoridade". Trad. Leyla Perrone-Moisés. São Paulo: WMF Martins Fontes, 2007.

FERREIRA, Aurélio Buarque de Holanda. Novo dicionário da língua portuguesa. Rio de Janeiro: Nova Fronteira, 1975.

FONSECA, Ricardo Marcelo. Resenha - AGAMBEN, Giorgio Estado de exceção. Revista da Faculdade de Direito da Universidade Federal do Paraná, Curitiba, n. 41, p. 171-174, 2005.

FOUCAULT, Michel. Em defesa da sociedade. Trad. Maria Ermantina Galvão. São Paulo: Martins Fontes, 2002.

GOLUB, Philip S. Eclipse da democracia. Disponível em: <http://diplo.uol.com.br/2006-09,a1396> Acesso em: 6 ago. 2007.

MARTINEZ, Vinício C. A modernidade perdeu a razão: para uma sociologia do Estado de Exceção. Disponível em: <http://jus2.uol.com.br/doutrina/texto.asp?id=9313>. Acesso em: 7 ago. 2007.

MOUFFE, Chantal. The political, the moral and the juridical. Texto ainda não publicado. 
SCHIER, Paulo Ricardo. Novos desafios da filtragem constitucional no momento do neoconstitucionalismo. A \& C Revista de Direito Administrativo e Constitucional, Belo Horizonte, a. 5, n. 20, p. 145-165, abr./jun. 2005.

VIEHWEG, Theodor. Tópica y jurisprudência. Madrid: Taurus, 1964. 